\title{
HBT TECHNOLOGY FOR HIGH POWER X BAND AND BROADBAND AMPLIFICATION.
}

\author{
P.F. ALLEAUME* ${ }^{*}$ Ph. AUXEMERY**, J.P. VIAUD*, H. BLANCK** , M. LAJUGIE* \\ *Thomson-CSF Microelectronique \\ 29 av CARNOT 91349 MASSY Cedex France. \\ ** United Monolithic Semiconductors \\ Route départementale 12891401 ORSAY Cedex France. \\ Pierre-Franck.Alleaume@TCM.THOMSON-CSF.COM \\ Philippe.AUXEMERY@UMS-GAAS.COM \\ Jean-Pierre.VIAUD@TCM.THOMSON-CSF.COM \\ Hervé.BLANCK@UMS-ULM.DE \\ Monique.LAJUGIE@TCM.THOMSON-CSF.COM
}

\begin{abstract}
For many applications like active phased array antennas for airborne radar, high power levels are required. To provide high performance and high manufacturing yield at a reduced coast, a MMIC solution is naturally very attractive. This can be achieved by choosing an efficient technology for active components. In this paper, a solution based on the HBT technology is presented.

The 10W class, $\mathrm{X}$ band power amplifiers, and $1 \mathrm{~W}, 4.5 \mathrm{GHz}-18 \mathrm{GHz}$ amplifiers were designed using the HBT technology HB20P from UMS. Based on the results obtained, this paper will discuss the capability and the technology improvements needed to reach the power and frequency bandwidth specifications with margin.
\end{abstract}

\section{INTRODUCTION}

Airborne radar and electronic warfare applications deal with high power systems. Of course, the available power level of the active components is the major limitation to reach the final performance of the system. So the choice of the technology used for power amplification functions is important. Many publications have presented the power level improvements for the most efficient MMIC technology such as MESFET, PHEMT or HBT. In this study, HPA circuits were designed using a HBT technology. This choice is directly linked with the maximum HF current and voltage available in with HBT. In the case of the UMS technology, the maximum RF power available is around $1.7 \mathrm{~kW} / \mathrm{mm}^{2}$ with a maximum Ice current around
$333 \mathrm{~A} / \mathrm{mm}^{2}$ in compression mode and a maximum value for Vce around $17 \mathrm{~V}$.

Two successive runs of $\mathrm{X}$ band and wide-band HPA were designed. The measured performance will be presented. The UMS HBT power technology is going to be described first.

\section{UMS HBT PROCESS DESCRIPTION}

The process is based on an GalnP/GaAs emitter/base junction. The base is highly carbondoped. High breakdown voltage is achieved with a thick GaAs collector layer. The process uses a conventional mesa approach and a non-selfaligned base contact. To enhance the reliability an emitterbase ledge is introduced. All optical lithography steps are performed by stepper lithography. Selective dry etching and a deep high-dose proton isolation are also applied. In order to improve the thermal stability of the transistors, a resistive layer is incorporated inside the emitter structure to provide an integrated emitter ballast resistance. Also, a thick layer of gold is used for the emitter air-bridge contacts, which plays the role of an efficient channel for heat sinking. These emitter ballast resistances and thermal drains warrant thermal stability and prevent thermal runaway.

\section{X BAND HPA}

\section{A. Design Goals}

Main design goals for the X Band HPA are output power greater than $5 \mathrm{~W}$, power added efficiency (PAE) better than $30 \%$ associated with $14 \mathrm{~dB}$ linear gain. The frequency bandwidth is $9 \mathrm{GHz}$ to $10.5 \mathrm{GHz}$. 
A $1 \mathrm{~W}$ class amplifier was also designed to drive this HPA. The needed linear gain is around $14 \mathrm{~dB}$.

\section{B. HPA Structure}

The circuit is a two stage amplifier, including four transistors with 8 base fingers of $2 \mu \mathrm{m} * 30 \mu \mathrm{m}$ for the first stage, and 8 transistors with 8 base fingers of $2 \mu \mathrm{m} * 40 \mu \mathrm{m}$ for the second stage. This structure presents a maximum output power of around $10 \mathrm{~W}$ at $10 \mathrm{GHz}$. The transistors are recombined two by two for stability and mismatch optimization (Fig. $1)$.

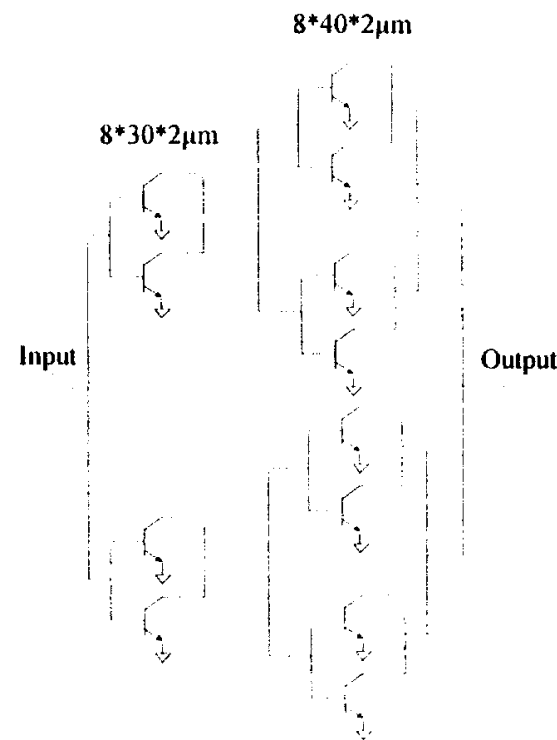

Fig. 1: $X$ band HPA HF structure

Chip size is $4500 \mathrm{~mm}$ by $4500 \mu \mathrm{m}$ (fig. 2).

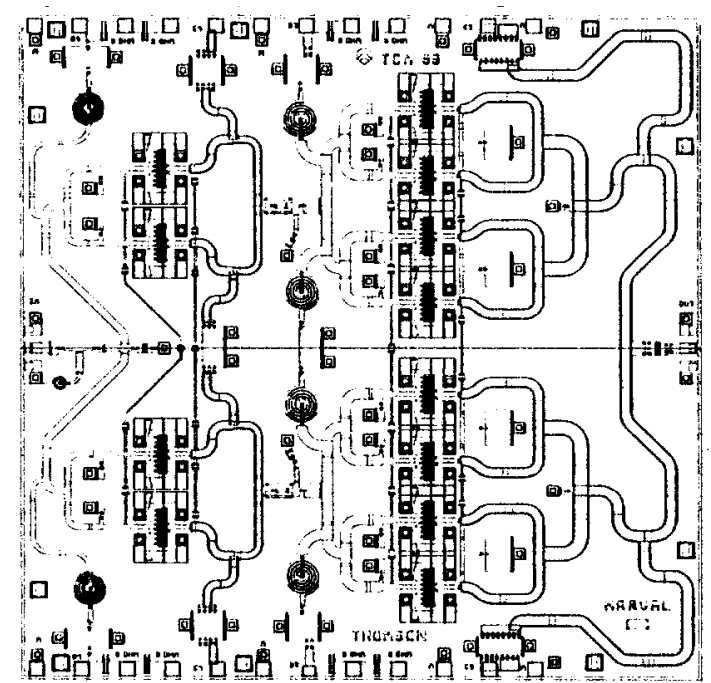

Fig. 2: X band HPA layout.

\section{Driver structure.}

This driver is a two stage amplifier with 4 base fingers of $2 \mu \mathrm{m} * 30 \mu \mathrm{m}$ transistor for the first stage, and two 6 base fingers of $2 \mu \mathrm{m} * 30 \mu \mathrm{m}$ transistors for the second one.

\section{D. $X$ band measurements results.}

Test-fixture measurements have been performed under pulsed conditions (both DC and RF, 10\% duty cycle). The output power versus frequency (for $10 \mathrm{~V}$ collector voltage) is drawn for 4 input power levels $(+4 \mathrm{dBm},+13 \mathrm{dBm},+18 \mathrm{dBm},+24 \mathrm{dBm})$ on figure 3 for the first run circuits.

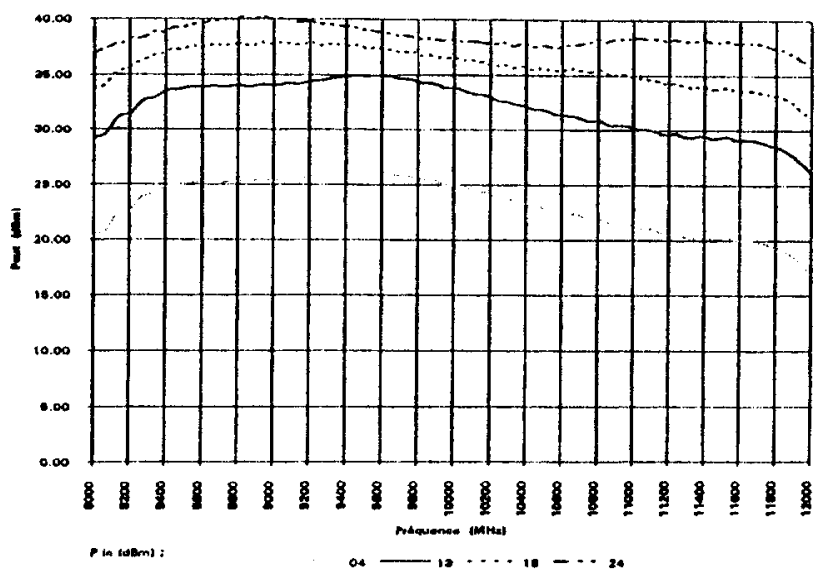

Fig 3: $1^{\text {st }}$ run X Band HPA : Measured Output power versus frequency.

For an input power of $24 \mathrm{dBm}$, the output power is greater than $5 \mathrm{~W}(37 \mathrm{dBm})$ over frequency band. At $9 \mathrm{GHz}, 10 \mathrm{~W}$ output power is achieved, associated with $35 \%$ PAE and $16 \mathrm{~dB}$ gain.

Output power design goals have been reached with a first pass. So, the need of a second run is mainly related to the improvement of small signal gain flatness over frequency band.

Last stage transistor periphery is the same as for the first run. $2^{\text {nd }}$ design work has been strongly assumed by the redesign of the inter-stage, due to back simulation data and also linked with a technological evolution.

At time, we don't have finished the measurement campaign for the second run. But, as shown by figure 4 , the study of the driver $\mathrm{S} 21$ parameter in RF pulsed mode $(10 \%)$ points out the improvement of the flatness for its response. This measurement has been done for 14 power points included between $-2 \mathrm{dBm}$ and $+18 \mathrm{dBm}$ versus frequency. Two curves are done: (a) for collector bias set to $6 \mathrm{~V}$ and (b) for $10 \mathrm{~V}$. 

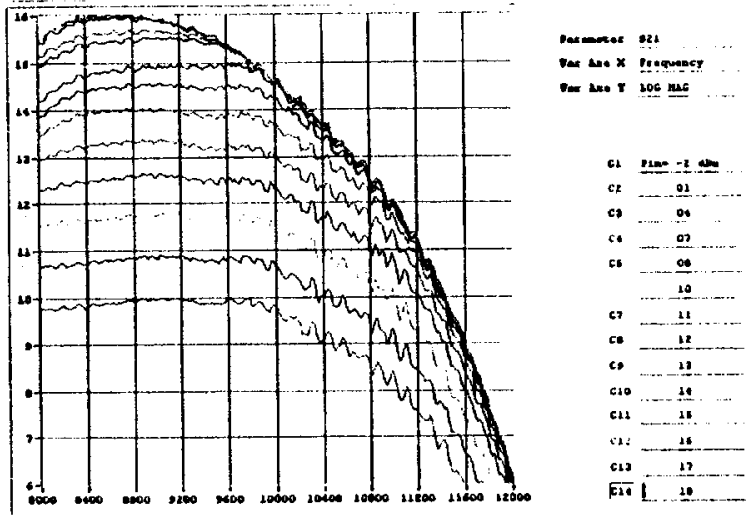

Fig. $4(a): 2^{\text {nd }}$ run $X$ driver : S21 pulsed response versus frequency depending input power level. $\mathrm{Vce}=6 \mathrm{~V}$.
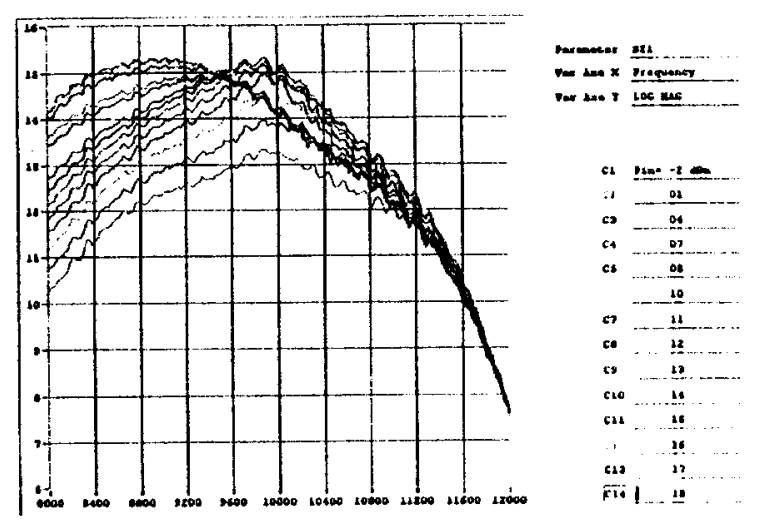

Fig. $4(b): 2^{\text {nd }}$ run $X$ driver : $S 21$ pulsed response versus frequency depending input power level.

$$
\mathrm{Vce}=10 \mathrm{~V} \text {. }
$$

This first result confirms the validity of the simulated results.

So, non-linear simulation results for the HPA are presented here after (Fig. 5):

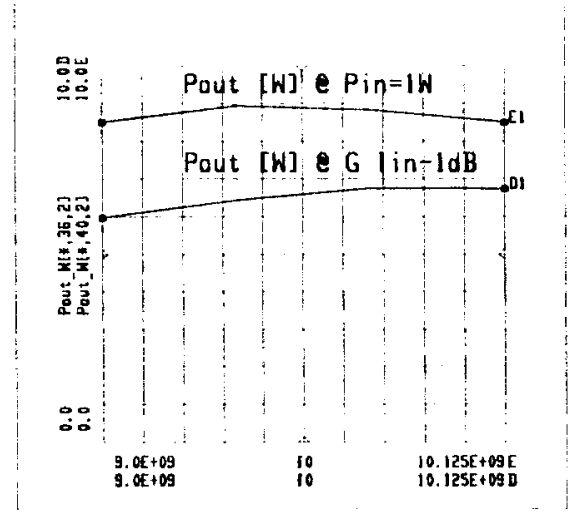

Fig.5: Output power versus frequency.

\section{BROAD BAND [4.5GHz-18GHz] HPA}

\section{A. Design Goals}

Main design goals for wide band HPA are output power greater than $1 \mathrm{~W}$, power added efficiency (PAE) better than $20 \%$ associated to $10 \mathrm{~dB}$ linear gain. The frequency bandwidth is $4.5 \mathrm{GHz}$ to 18 $\mathrm{GHz}$.

\section{B. Circuit Structure}

The designed circuits are two stage amplifiers including two 8 base fingers of $2 \mu \mathrm{m} * 20 \mu \mathrm{m}$ transistors for the first stage, and four 6 base fingers of $2 \mu \mathrm{m} * 30 \mu \mathrm{m}$ for the second stage. The output stage provides an available output power greater than $1.5 \mathrm{~W}$.

The chip size is $4300 \mu \mathrm{m} * 3000 \mu \mathrm{m}$ (see figure 6).

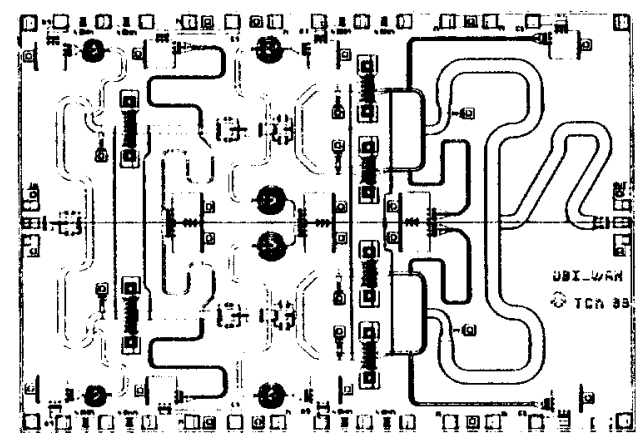

Fig 6 : Wide Bad HPA Layout

\section{1st Run Measurement Results}

Test fixture measurements have been performed under pulsed conditions (both DC and RF, $10 \%$ duty cycle). The output power versus frequency (for $8 \mathrm{~V}$ collector voltage) is drawn for 4 input power levels $(+1 \mathrm{dBm},+10 \mathrm{dBm},+16 \mathrm{dBm},+21 \mathrm{dBm})$ on figure 7 .

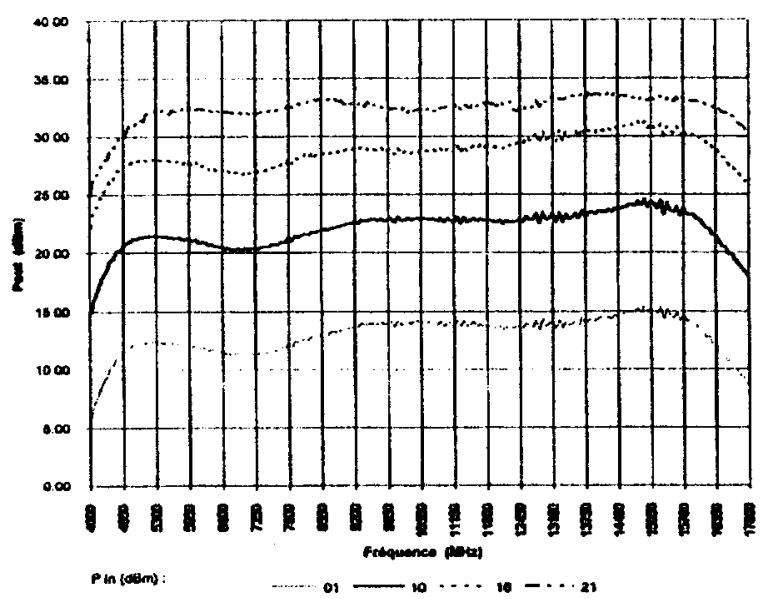

Fig. 7. Broad band HPA : Measured Output power versus frequency. 
For an input power of $21 \mathrm{dBm}$, the output power is $1.5 \mathrm{~W}(32 \mathrm{dBm})$ from $4.5 \mathrm{GHz}$ up to $16 \mathrm{GHz}$, associated with more than $20 \%$ power added efficiency (PAE).

\section{D. $2^{\text {nd }}$ Run, simulated and measured Data.}

Design goal output power has been demonstrated over 4.5 to $16 \mathrm{GHz}$ with this first run. So, the $2^{\text {nd }}$ run is needed to increase frequency band up to $18 \mathrm{GHz}$.

Back simulation, pointed out that the main limitation for operation up to $18 \mathrm{GHz}$ was related to the transistor topology itself (it's strongly necessary to decrease parasitic elements). So, the $2^{\text {nd }}$ run, main work has been dedicated to introduce in the design new specific wide band transistor cells provided by UMS.

Small signal simulated data are given here after (figure 8).

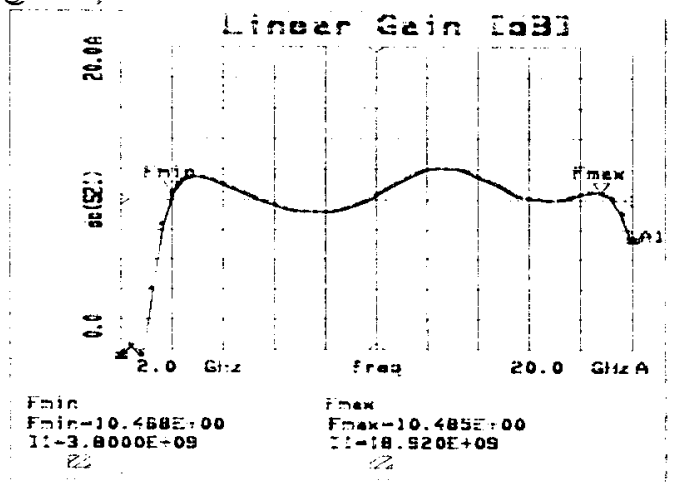

Fig. 8.: Wide band $2^{\text {nd }}$ Run Simulated [S] parameters.

This $2^{\text {nd }}$ run has be completed last June, so at time we have on wafer measurements. Figure 9 presents on wafer power measurements versus frequency.

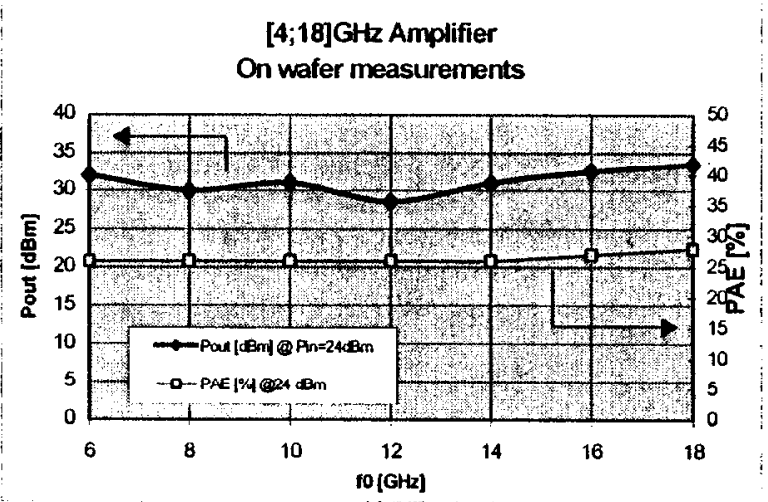

Fig. 9. : Wide band $2^{\text {ud }}$ Run, output power \& PAE yield, On wafer measurements.
These first results point out the enlargement of the frequency band to $18 \mathrm{GHz}$. The poor flatness of the power response of the circuit can be explain by onwafer low frequency oscillations. This classical matter will probably be solved in jig tests.

\section{CONCLUSIONS}

A first run of $\mathrm{X}$ band and wide band HPA has been manufactured and tested, using HBT process from UMS (HB20P process).

These 2 circuits exhibit :

- more than $5 \mathrm{~W}$ output power for X band HPA ( up to $10 \mathrm{~W}$, associated to $35 \%$ PAE)

- $\quad 1.5 \mathrm{~W}$ output power over 4.5 to $16 \mathrm{GHz}$, associated to $20 \%$ PAE for wide band HPA.

So, high power performance has been demonstrated with HBT "HB20P" process.

A second run has been launched in order to improve gain behavior over frequency band, using new topology transistor cells. First measurement results that will be completed for the conference point out that the power performances are reached

\section{REFERENCES}

[1] - M. A. KHATIBZADEH, W. LIU, 'I'. HENDERSON, J. SWEDER, S. PIERCE

"High-efficiency X band HBT power amplifier."

IEEE MMWMC Symp., p117-127, May 1994, San Diego.

[2] - F. ALI, A. GUPTA, M. SALIB, B. VEASEL, D. DAWSON

"A 2 watt, 8-14 GHz HBT power MMIC with $20 \mathrm{~dB}$ gain and $>40 \%$ power added efficiency."

IEEE transactions, vol. 42, $\mathrm{N}^{\circ} 12$, p2635-2641, December 1994.

[3] - F. ALI, M. SALIB, A. GUPTA, D. DAWSON

"An $8-15 \mathrm{GHz}, 1 \mathrm{~W}$ HBT power MMIC with $16 \mathrm{~dB}$ gain and $48 \%$ peak power added efficiency."

IEEE GaAs IC Symp. Digest, pp 363-366, Oct 1993.

[4] - J. J. KOMIAK, L. W. YANG

"5 Watt high efficiency wideband 7 to $11 \mathrm{GHz}$ HBT MMIC power amplifier.'

IEEE MMWMC Symp., p17-20, May 1995, Orlando.

[5] - J. P. VIAUD, M. LAJUGIE, R. QUERE, J. OBREGON

"First demonstration of a $0.5 \mathrm{~W}, 2$ to $8 \mathrm{GHz}$ MMIC HBT distributed power amplifier based on a large signal design approach".

IEEE MMT-S Digest, vol. 2, pp 893-896, June 1997. 